\title{
A bibliografia como ciência [Tradução do artigo de GUILD, Reuben A. Bibliography as science. American Library Journal, v. 1, n. 2-3, p. 67-69, nov. 1876.]
}

Laffayete de Souza Alvares Júnior

Mestre em Ciência da Informação pelo Programa de Pós-Graduação em Ciência da Informação IBICT - UFF. Professor Assistente - Unirio.

Gustavo Silva Saldanha

Doutor em Ciência da Informação pelo Programa de Pós-Graduação em Ciência da Informação IBICT - UFRJ. Pesquisador Adjunto - IBICT. Professor Adjunto - Unirio.

http://dx.doi.org/10.1590/1981-5344/3241

Recebido em 31.05.2017. Aceito em 30.06.2017

"Bibliografia", termo oriundo de duas palavras gregas, $\beta \imath \beta$ ıov e $\gamma \rho \alpha \phi o \omega$, significa, literalmente, a descrição de livros. Entre os gregos, o termo $\mathrm{B} \imath \beta \lambda \iota \gamma \rho \alpha \phi \imath \alpha$ significava a escrita ou a transcrição de livros e o bibliógrafo, para eles, era, meramente, o escrivão de livros, no sentido de um copista. O termo francês Bibliographie foi há muito usado para denotar uma intimidade com antigos textos ou manuscritos e com a arte de decifrá-los. Este ramo do conhecimento é agora considerado sob o termo mais moderno "paleografia". A publicação de Bibliographie Instrusctive, de De Bure, em 1763, marcou uma era na história da bibliografia como ciência e contribuiu mais do que qualquer outro trabalho para tornar seu estudo popular e atraente.

Num sentido moderno e mais amplo, bibliografia pode ser definida como CiÊNCIA OU CONHECIMENTO DO LIVRO no que se refere aos materiais com os quais são compostos, os diferentes graus de raridade, curiosidade, valor real ou reputado, os assuntos discutidos por seus respectivos autores e o renque onde devem ser mantidos na classificação de uma 
biblioteca. Esta ciência está, portanto, dividida em dois ramos. O primeiro se refere aos conteúdos dos livros e pode ser chamado - na falta de um termo melhor - BIBLIOGRAFIA INTELECTUAL. $O$ segundo trata das características externas dos livros, suas formas, preços e variedade, os nomes das editoras, da data e do lugar de publicação e a história das cópias e edições específicas. Isso pode ser chamado BIBLIOGRAFIA MATERIAL. ESTA Envolve o conhecimento da arte de publicação - não de fato como processo mecânico, mas sua história e desdobramentos, e, na verdade, de todas as partes constituintes dos livros, como meio de identificar produções específicas. Ricos amadores, colecionadores de livros curiosos e raros, antiquários, pessoas envolvidas no comércio literário e bibliotecários em geral cultivam muito zelosamente esse ramo da ciência, o qual Dibdim denominou com humor "Bibliomania ou book-madness" (1).

O objetivo da BibliogRAFIA INTELECTUAL é apresentar aos homens de literatura os mais importantes livros em cada campo de estudos, tanto por meio de catálogos classificados, quanto de catálogos similares e alfabéticos, acompanhados de notas críticas e bibliográficas. Essa espécie de conhecimento foi cultivada com mais sucesso na França, Alemanha e Itália, países aos quais devemos, especialmente ao primeiro, nossas obras mais úteis, tanto em bibliografia geral quanto em bibliografia especializada. Isso, sem dúvida, se deve, em grande medida, ao acesso livre do público a todas as grandes bibliotecas, ao grande número de coleções privadas e à consequente familiaridade de seus homens de literatura e ciência com livros e manuscritos de todas as idades e países. As pesquisas de Brunet, Barbier, Renouard e Quérard, Ebert, Ersch, Graesse e Petzholdt, Fontanini, Tiraboschi e Gamba, serão mantidas em grata lembrança por todos os amantes do estudo.

$\mathrm{Na}$ Inglaterra, a bibliografia como ciência recebeu menos atenção do que no continente, apesar de seu imbatível British Museum e sua riqueza de recursos literários. As obras, no entanto, de Clarke, Horne, Lowndes, Dibdin e Watt são excepcionalmente valiosas e instrutivas, à altura da produção de seus contemporâneos continentais.

Em nosso próprio país, tal ciência foi muito naturalmente negligenciada até um período comparativamente recente. No entanto, devido a uma difusão geral do conhecimento e da riqueza, e da rápida formação e desenvolvimento de bibliotecas de todos os tipos, agora a Bibliografia tem recebido crescente atenção. A prova disso é esta Centennial Conference of Librarians (2), a primeira do tipo já ocorrida no mundo, sem contar a Convenção de 1853, ao menos até onde sabemos. A habilidade profissional e trabalhos de Folson e Boswell, Ticknor e Jewett são bem conhecidos e apreciados, mesmo em países mais antigos. Comemoramos o abrangente Dictionary of English and American Authors, por Allibone, que atende aos desejos acadêmicos nos dois hemisférios. Congratulamo-nos mutuamente sobre a superioridade reconhecida de nosso sistema de catalogação, introduzido pelo Professor Jewett na Public Library of Boston e, desde então, adotado por nossas principais bibliotecas públicas por todo o país. $\mathrm{E}$ orgulhamo-nos de nossos caros e belos 
edifícios construídos ou em processo de construção para museus e coleções de livros.

Devido aos muitos devotos da bibliografia, especialmente na França, tem-se exagerado o valor da prática bibliográfica para muito além da posição que lhe seria coerente na escala do conhecimento humano. Escritores como Peignot e Achard apresentam a bibliografia como a maior das ciências, incluindo, na verdade, todas as outras. Nada certamente pode ser mais absurdo do que observá-la sob esta luz meramente porque ela trata dos livros, e porque os livros são veículos de toda sorte de conhecimento. Aliás, esse é o único fundamento que se encontra para estas extravagantes representações, que tendem, como em qualquer outro caso de pretensões exageradas, expor ao ridículo um assunto que, quando sua natureza e objetos são corretamente definidos, não deixará de parecer importante como a serva da literatura, por assim dizer, e um apoio essencialíssimo para a ciência e a arte.

Em concordância ao que foi ora estabelecido, é do âmbito do bibliógrafo, ou, se podemos colocar desta forma, do bibliotecário, estar familiarizado com os materiais que compõem livros, suas diferentes formas ou tamanhos, os vários estilos de encadernação utilizadas, o número de páginas, as características tipográficas, o número e a descrição de chapas, a completude, a correção e todas as outras peculiaridades externas ou distinções de cada edição. Ele sabe não apenas os melhores tratados que foram escritos sobre qualquer tópico particular e seu valor comparativo, mas também as várias edições de livros e de importantes aspectos nos quais as várias edições diferem uma da outra; quando, e por que motivo, omissões foram feitas, deficiências supridas, erros corrigidos e adições anexadas. Quando livros são publicados, mesmo anônimos ou com pseudônimos, ele indica o nome real ou oculto do autor; e, com respeito à raridade dos livros, ele está familiarizado com as causas que os tornam raros. Finalmente, como uma biblioteca destituída de arranjo é um "caos e não um cosmos", ele dispõe os livros que a compõem numa ordem tal que ao mesmo tempo facilita a pesquisa e apresenta uma agradável aparência à vista; e na compilação de um catálogo que foi, com felicidade, descrito como o "olho da biblioteca", dá a eles títulos apropriados, designando no índice o lugar onde deveriam ocupar no mais rigoroso sistema de classificação.

Esses são deveres legítimos de um bibliógrafo, e, em certa medida, do bibliotecário, requerendo, do primeiro caso, uma variedade e amplitude de conhecimento raramente ou jamais possuído por um único indivíduo. Daí diferentes autores terem discutido assuntos específicos de bibliografia; e a partir da união de seus trabalhos pode-se coletar um multifacetado quadro de habilidades que constitui um bibliógrafo como tentamos descrever aqui. Uma coleção de todos os trabalhos desse tipo existentes, incluindo tanto referente à bibliografia geral quanto à específica, história literária e certa classe de periódicos e biografia universal, excederia, como estimado, vinte mil volumes. Na verdade, Namur, na sua Bibliographie, publicada em 1838, lista dez mil obras separados. Essa lista foi revisada e 
ampliada por Dr. Petzholdt em seu catálogo, notavelmente completo e abrangente, publicado em 1866, intitulado Bibliotheca Bibliographica.

Como conclusão, apontamos, brevemente, de um modo melhor,

1- Que a bibliografia pode ser considerada, se não como uma ciência prática, pelo menos como a serva de toda a ciência, literatura e arte.

2- Que a seleção minuciosa de trabalhos bibliográficos pode formar as bases de todas as coleções (públicas ou privadas) de livros. Eles são as ferramentas de acadêmicos, colecionadores e de bibliotecários.

3- Que em nossas faculdades e mais altas instituições de ensino, pessoas competentes devem ser empregadas para dar informação sobre os vários tópicos que a bibliografia inclui, dentro de um curso de lições comuns, como as que são ordinariamente dadas em geologia, zoologia, psicologia e várias outras ciências que figuram nos modernos currículos de cursos acadêmicos ou universitários.

\section{Notas}

(1) Obra de Thomas Frognall Dibdin (1776-1847), "Bibliomania or Book-Madness: a bibliographical romance", publicada em Londres em 1809.

(2) Convenção de bibliotecários e livreiros ocorrida em setembro de 1853 nos Estados Unidos com o intuito de constituir a profissionalização das práticas biblioteconômicas. Trata-se de uma das bases da futura American Library Association.

(3) Reconhecido encontro de fundação da American Library Association no ano de 1876. 